\title{
Aporte nutricional no tratamento do vírus da imunodeficiência (HIV)
}

\author{
Nutricional support in the treatment of human immunodeficienc u vírus (HIV) \\ Apoyu nutricional em el tratamento del vírus de inmunodeficienci a humana (VIH)
}

Recebido: 21/05/2021 | Revisado: 28/05/2021 | Aceito: 31/05/2021 | Publicado: 13/06/2021

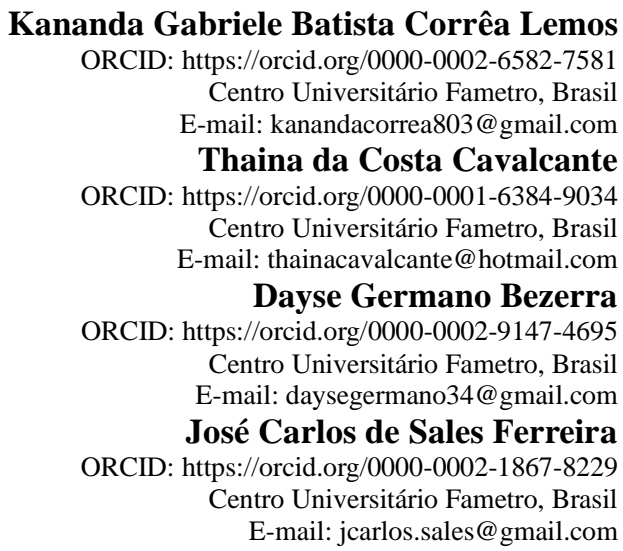

\begin{abstract}
Resumo
Introdução: A infecção pelo vírus da imunodeficiência humana (HIV) é considerada uma grande problemática no que se refere a saúde pública, pois o seu crescente número de casos no mundo é alarmante. Objetivo: Analisar o aporte nutricional indicado para pacientes em tratamento do HIV/AIDS. Metodologia: Para a realização desse estudo optouse por uma pesquisa na modalidade de revisão integrativa de literatura. Resultados e Discussão: O vírus da imunodeficiência humana (HIV) caracteriza-se como uma doença de alta letalidade que pode vir a causar danos irreparáveis ao ser humano. Sabe-se que o risco de infecção oportunista relacionada a esse vírus em pessoas infectadas com aumenta enquanto a contagem de CD4+ diminui. Conclusão: Recomenda-se que todo paciente infectado pelo HIV seja encaminhado ao profissional nutricionista logo após o primeiro diagnóstico para avaliação do seu perfil.
\end{abstract}

Palavras-chave: Nutrição; Imunodeprimidos; Tratamento.

\begin{abstract}
Introduction: Infection with the human immunodeficiency virus (HIV) is considered a major problem with regard to public health, as its growing number of cases in the world is alarming. Objective: To analyze the nutritional intake indicated for patients undergoing treatment for HIV / AIDS. Methodology: In order to carry out this study, a research was chosen in the form of an integrative literature review Results and Discussion: The human immunodeficiency virus (HIV) is characterized as a highly lethal disease that can cause irreparable damage to the human being. It is known that the risk of opportunistic infection related to this virus in people infected with it increases as long as the CD4 + count is present. Conclusion: It is recommended that every HIV-infected patient be referred to a nutritionist immediately after the first diagnosis to assess their pro.
\end{abstract}

Keywords: Nutrition; Immunodepressed; Treatment.

\section{Resumen}

Introducción: La infección por el virus de la inmunodeficiencia humana (VIH) se considera un problema importante en materia de salud pública, ya que su creciente número de casos en el mundo es alarmante. Objetivo: Analizar la ingesta nutricional indicada para pacientes en tratamiento por VIH / SIDA. Metodología: Para la realización de este estudio se optó por una investigación en la modalidad de revisión integradora de la literatura. Resultados y Discusión: El virus de la inmunodeficiencia humana (VIH) se caracteriza por ser una enfermedad altamente letal que puede causar daños irreparables a los humanos. Se sabe que el riesgo de infección oportunista relacionada con este virus en personas infectadas por el VIH aumenta mientras que el recuento de CD4 + disminuye. Conclusión: Se recomienda que todo paciente infectado por el VIH sea derivado a un nutricionista inmediatamente después del primer diagnóstico para evaluar su perfil.

Palabras clave: Nutrición; Inmunodeprimido; Tratamiento. 


\section{Introdução}

A infecção pelo vírus da imunodeficiência humana (HIV) é considerada uma grande problemática no que se refere a saúde pública, pois o seu crescente número de casos no mundo é alarmante. De acordo com Silva e Libonati (2020), ao final de 2010, cerca de 62 milhões de pessoas no mundo estavam infectadas com o vírus da imunodeficiência humana (HIV) e 95\% delas pertenciam ao terceiro mundo, ou seja, em países subdesenvolvidos, onde os recursos são menores. Sabe-se ainda que esta doença tem um impacto significativo na nutrição do indivíduo doente, família e comunidade, causando muitas vezes uma perda de peso maior que $10 \%$.

No Brasil, de 2007 até junho de 2016, foram notificados, no Sistema de Informação de Agravos de Notificação (Sinan), 136.945 casos de infecção pelo HIV. Quando relacionado a maior incidência, o sexo masculino se destacou com uma relação de 2,4 homens a cada mulher infectada. É evidenciado ainda que a maioria dos casos de infecções pelo vírus HIV se encontra nas faixas de 20 a 34 anos em 52,3\% dos casos (Brasil, 2016; Malta et al., 2016).

É citado por Silva et al. (2015), que a infecção pelo vírus da imunodeficiência humana (HIV) acelera o ciclo vicioso de ingestão inadequada de alimentos levando à desnutrição que por sua vez promove a progressão da doença, aumentando assim a vulnerabilidade imunológica do indivíduo, o expondo a diversos impactos pós-infecção e o condicionando a evolução de um prognóstico ruim da doença. É referido por Santos et al. (2020), que a desnutrição aumenta ainda mais a imunodeficiência, podendo comprometer os resultados da terapia medicamentosa.

No que se refere à prevalência, a desnutrição é considerada comum em pacientes com vírus da imunodeficiência humana (HIV), sendo ainda mais evidenciado nos estágios avançados da doença. A terapia nutricional nos pacientes com esse nível de comprometimento pode reduzir a mortalidade, melhorando os resultados terapêuticos da doença, reduzindo custos e internações e, sobretudo, melhorando a qualidade de vida desses pacientes, que passam a ter uma condição melhor de vida quando ainda associada a atividades esportivas e a praticas saudáveis que remetem a melhor qualidade de vida (Braga, Guimarães \& Figueiredo, 2015; Silva et al., 2016).

De acordo com Souza et al. (2018), pacientes com vírus da imunodeficiência humana (HIV) que desenvolvem a doença podem emagrecer rapidamente em média de $5 \mathrm{~kg}$ por mês quando associado a uma infecção secundária sistêmica em mais de $80 \%$ dos casos, ou emagrecer mais lentamente, $1 \mathrm{~kg}$ por mês em média, indicando uma doença gastrintestinal, podendo ser esta candidíase, criptosporidiose, ou outras, ou até mesmo pela redução na ingestão alimentar através da nutrição inadequada de alimentos.

Sendo assim, é de fundamental importância que os pacientes acometidos por essa comorbidade sejam orientados sobre hábitos alimentares, para que tenha uma melhora ou recuperação do seu estado nutricional e da sua qualidade de vida. Quando em crianças acometidas pelo vírus da imunodeficiência humana (HIV), o aporte nutricional deve ser individualizado e monitorado de acordo com cada caso e de acordo com as suas especificidades (Kubrusly et al., 2015; Ribeiro etal., 2015).

Nesse contexto, a Organização mundial da saúde (OMS), determinou que as intervenções nutricionais façam parte de todos os programas voltados ao controle e tratamento do vírus da imunodeficiência humana (HIV), uma vez que, a dieta e a nutrição podem ajudar na efetividade da terapia antirretroviral minimizando seus efeitos colaterais e aumentando a qualidade de vida do portador desse vírus (Brasil, 2013).

Com isso, nota-se que a nutrição exerce um papel de suma importância na vida dos portadores do vírus da imunodeficiência humana (HIV), uma vez que, realizar uma intervenção nutricional voltada para manutenção e boa evolução do estado nutricional do portador contribuirá para melhoria da sua absorção de nutrientes, mantendo seu sistema imunológico eficiente, diminuindo os sintomas causados e melhorando a adesão e efetividade da terapia antirretroviral, promovendo mais saúde a esses indivíduos e uma melhor qualidade de vida (Tshingani et al., 2017; Fisher et al., 2019). 
De acordo com o que foi abordado, sabe-se que após a terapia antirretroviral de alta potência, a questão da desnutrição permanece prevalente em nosso meio se tornando um grande desafio no tratamento do HIV/AIDS, o que causa a necessidade de conhecer mais a fundo a causa da desnutrição nesses pacientes (Flores-López \& Flores-Arenales, 2020).

Considerando que essas informações são necessárias para guiar estratégias para a realização do diagnóstico precoce, também orientar um tratamento nutricional individualizado para aqueles com fatores de risco, de modo a reduzir a ocorrência e o impacto da desnutrição, justifica-se a realização do presente trabalho tendo em vista o bem-estar de parte da população envolvida na temática abordada. Contudo o objetivo geral deste artigo é analisar o aporte nutricional indicado para pacientes em tratamento do HIV/AIDS.

\section{Metodologia}

Para a realização desse estudo optou-se por uma pesquisa na modalidade de revisão integrativa de literatura. A revisão integrativa determina o conhecimento atual sobre uma temática específica, já que é conduzida de modo a identificar, analisar e sintetizar resultados de estudos independentes sobre o mesmo assunto (Silveira et al., 2008).

A Revisão Integrativa é um método de pesquisa apontado como ferramenta de grande relevância no campo da saúde, por proporcionar a busca, a avaliação crítica e a síntese de evidências sobre um tema investigado. Esses aspectos facilitam a identificação dos resultados relevantes, de lacunas que direcionam para o desenvolvimento de futuras pesquisas e auxiliam o profissional a escolher condutas e a tomar decisões, proporcionando um saber crítico (Souza, Silva \& Carvalho, 2010).

Para extrair os dados dos artigos selecionados, será necessária a utilização de um instrumento previamente elaborado capaz de assegurar que a totalidade dos dados relevantes seja extraída, minimizar o risco de erros na transcrição, garantir precisão na checagem das informações e servir como registro (Souza, Silva \& Carvalho, 2010).

A coleta das informações para a pesquisa bibliográfica será por meio da exploração da base de dados da Biblioteca Virtual em Saúde (BVS), Biblioteca Cientifica Eletrônica Virtual (SCIELO) e Literatura Latino-Americana e do Caribe em Ciências da Saúde (LILACS).

A busca na base de dados será orientada pelos descritores: Nutrição, Imunodeprimidos, Tratamento, e será realizado em todos os índices, buscando captar o maior número de artigos publicados no período proposto que abordem a temática em discussão, visando o desenvolvimento fidedigno desse estudo.

Para uma análise crítica e reflexiva dos estudos incluídos na revisão, será realizada uma leitura minuciosa e criteriosa destacando os que atingirem os critérios de inclusão e que contemplarem o objetivo proposto, para viabilizar o resultado da pesquisa de forma objetiva.

Serão incluídos os artigos publicados em língua portuguesa nos últimos dez anos, com texto completo, disponível online, com acesso livre. Serão excluídos da amostra os artigos publicados em línguas estrangeiras, os que não apresentarem o texto na integra, artigos que não apresentavam relação direta com o tema, resumos, monografias, dissertações, teses e artigos repetidos.

\section{Resultados e Discussão}

\subsection{A origem do HIV}

No que se refere à origem do vírus da imunodeficiência humana, nada é muito esclarecido, o que se sabe é que os primeiros casos foram detectados na África e nos Estados Unidos e a epidemia passou a adquirir importância nos anos de 1980. Várias hipóteses foram levantadas, dentre as quais a de que o vírus precursor tenha passado de primatas para o homem, permanece sem uma explicação plausível, e mais ainda, porque após milhares de anos de coexistência de homens e primatas no 
Continente Africano, somente agora se deu a emergência da infecção humana pelo vírus aidético (Silva \& Cueto, 2018; Zamboni, 2015).

Nesse contexto, acredita-se que o vírus da imunodeficiência humana (HIV) tenha se originado em primatas no centrooeste africano e foram transferidos para os seres humanos no início do século XX, através de humanos que participavam de atividades com animais selvagens, como caçadores ou vendedores de animais silvestres, sendo infectados a partir destes. Outra hipótese levantada é que as práticas médicas inseguras na África após a Segunda Guerra Mundial, como a reutilização de seringas não esterilizadas durante programas de vacinação em massa, uso de antibióticos e de campanhas de tratamento antimalárica, foram os vetores iniciais que permitiram que o vírus se espalhasse e se adaptasse aos seres humanos (Ferreira, 2019; Valle,2018).

Dentre estas, várias foram as hipóteses levantadas acerca da origem desse vírus letal, indo desde a simples questão de oportunidade e deste vira se tornar mais frequente em virtude das mudanças sociais resultantes da aglomeração urbana e do intercâmbio extremamente desenvolvido. Há também os que admitem a influência das transfusões sanguíneas experimentais realizadas, no decurso deste século, para estudos de malária. Contudo, nenhuma delas é capaz de trazer explicações incontestáveis sobre a questão (Thomaz, 2018; Aggleton \& Parker,2015).

Nesse seguimento é relatado por Souza, Suassuna e Costa (2016), que os agentes infecciosos apresentam a possibilidade de emergirem sob novas formas para dar origem a epidemias. Algumas revelam-se associadas às mudanças do comportamento humano enquanto outras surgem de novas expressões gênicas. De acordo com Moyer (2015), é conhecido o fato de a rapidez da taxa mutacional do vírus da imunodeficiência humana (HIV) resultar em grande potencial de mudanças nas taxas de replicação. É por isso que, fora do período de latência, o vírus desenvolve- se intensamente no intervalo entre o surgimento dos sinais clínicos e a morte.

Concernente a isso, é relatado por Morales e Garcia (2015), que inicialmente os casos foram prevalentes em dois grupos, entre os usuários de drogas injetáveis e entre homens homossexuais que apresentavam a imunidade comprometida sem motivo aparente. Dentre as comorbidades que se manifestavam pode-se destacar a pneumonia pelo fungo Pneumocystis carinii (PCP), uma infecção oportunista incomum até então, conhecida por ocorrer em pessoas com o sistema imunológico muito debilitado.

É referido por Pereira e Monteiro (2015), que pouco depois, um número inesperado de homens gays desenvolveu um tipo de câncer de pele raro chamado sarcoma de Kaposi, seguindo com complicações diversas e manifestações que se conheceram ao seguir dos tempos.

\subsection{O Vírus Da Imunodeficiência Humana (HIV) e as doenças oportunistas}

O vírus da imunodeficiência humana (HIV) caracteriza-se como uma doença de alta letalidade que pode vir a causar danos irreparáveis ao ser humano. Sabe-se que o risco de infecção oportunista relacionada a esse vírus em pessoas infectadas com aumenta enquanto a contagem de CD4+ diminui. O risco também aumenta em pacientes que não estão recebendo ou que não respondem à terapia antirretroviral, deixando estes susceptíveis a adquirir doenças oportunistas (Cruz-Jentoft, 2018; Abramovay, 2015).

De acordo com Filteau et al. (2017), para a maioria dos pacientes infectados pelo vírus da imunodeficiência humana (HIV) com uma infecção oportunista aguda, a terapia antirretroviral deve ser considerada nas primeiras duas semanas do início do tratamento da infecção oportunista aguda. No entanto, para Lima et al. (2017), na tuberculose poderia ser mais conveniente esperar por uma resposta terapêutica antes de iniciar a terapia antirretroviral, levando em consideração que esta pode estar associada a outras doenças oportunistas. 
É relatado por Ledo et al. (2017), que o imuno comprometimento também favorece as infecções por múltiplos e diversos tipos de agentes infecciosos, o que reduz a qualidade de vida deste paciente. Em pessoas soropositivas a prevalência das parasitoses intestinais é maior quando são comparados com indivíduos não portadores do vírus. É importante também ressaltar que as parasitoses intestinais que atingem pacientes soropositivos variam de acordo com a região geográfica e com o nível endêmico de cada local. A diarreia causada pelas parasitoses é muito proeminente entre essas pessoas.

Nesse contexto, é importante frisar que as baixas taxas de T-CD4+ estão associadas a maior frequência de diarreia entre os pacientes com vírus da imunodeficiência humana (HIV) e parasitoses intestinais. Dessa forma, devido as interações entre os helmintos e o vírus da imunodeficiência humana (HIV), constatou- se que pessoas infectadas por helmintos têm sua resposta imune ativada cronicamente, o que causa uma desregulação imunológica e, até mesmo, uma ausência de resposta imune. Indivíduos parasitados por helmintos tornam-se mais suscetíveis a se infectar pelo vírus da imunodeficiência humana (HIV) e, uma vez infectados, a progressão da infecção viral ocorre mais rapidamente (Nogueira et al. 2019; Galvão et al. 2018).

Com isso, é referido por Sousa e Junior (2016), que o tratamento das doenças oportunistas consiste em curar apenas a doença presente no momento, não impedindo assim a reinfecção, sendo assim, o acompanhamento médico dos pacientes com o vírus da imunodeficiência humana (HIV) é essencial para diagnosticar e tratar rapidamente essas infecções, além de manter a contagem de célulasT-CD4+ dentro dos parâmetros desejados, sendo também necessário realizar o exame parasitológico de fezes regularmente.

\subsection{Os benefícios da nutrição adequada em pacientes portadores do vírus da imunodeficiência humana (HIV)}

O fator voltado a nutrição é caracterizado como um determinante quando relacionado a imunidade e a resposta imune a infecções. Nesta, o sistema imunitário do hospedeiro ativa inicialmente as defesas inatas e, subsequentemente, as defesas adquiridas. Por sua vez estes processos envolvem a ativação e proliferação das células imunitárias, que protegem o corpo contra coinfecções que atingem o corpo humano e por sua vez o paciente acometido pelo vírus da imunodeficiência humana (HIV) (Azevedo., Oliveira \& Soares, 2016., Costa et al., 2017).

De acordo com Silva et al. (2018), para que haja a ativação do sistema imunológico e consequentemente a resposta imunitária a infecções, é necessário que haja um consumo adicional de energia. Por outro lado, é relatado por Lenzi et al. (2015), que devido aos mediadores da resposta inflamatória há um aumento da resposta catabólica. Assim, verifica-se que a evolução da infecção tem ligação direta com o estado nutricional que o hospedeiro apresenta.

Ao que se refere aos casos de má nutrição corpórea, é importante frisar que existem dois tipos distintos, o qual podese destacar a má nutrição por déficit de ingestão energética ou nutricional e a má nutrição por excesso de ingestão energética ou nutricional. Contudo, nos pacientes com infecção pelo vírus da imunodeficiência humana (HIV) a má nutrição refere-se, geralmente, ao estado consequente do déficit, energético ou nutricional (Oliveira et al., 2018; Bezerra et al.,2016).

Sendo assim, de acordo com Pinto et al. (2016), nota-se que as recomendações nutricionais variam em função de diversos fatores. Neste sentido, os pacientes necessitam de uma dieta que proporcione todos os nutrientes essenciais para a satisfação das suas necessidades nutricionais acrescidas e assim contribua quer para a prevenção da perda de peso ou manutenção deste, quer para o combate à infecção bem como para o desenvolvimento ou manutenção da massa muscular.

O acompanhamento nutricional do paciente portador do vírus da imunodeficiência humana (HIV) inclui três componentes: a avaliação, intervenção e o seguimento/revisão nutricional. Devido ao risco elevado de complicações nutricionais, a intervenção baseada nos dados recolhidos por uma avaliação completa, deverá ocorrer logo após o diagnóstico de infecção pelo vírus. Por outro lado, é importante salientar que o seguimento, tal como a avaliação nutricional, são 
procedimentos essenciais para que haja uma ótima prestação de cuidados por parte do nutricionista (Oliveira, Leite \& Claro, 2015; Gonçalves \& Piccinini, 2015).

\section{Conclusão}

Recomenda-se que todo paciente infectado pelo HIV seja encaminhado ao profissional nutricionista logo após o primeiro diagnóstico para avaliação do seu perfil nutricional, determinando e priorizando intervenções dietoterápicas apropriadas através de metas individualizadas. A desnutrição e seus distúrbios devem ser prevenidos e/ou tratados através de metas eficientes apoiadas em três bases: avaliação, orientação e intervenção nutricional. A complexidade da avaliação, o tipo da orientação e o grau de intervenção devem variar com o estágio de doença do indivíduo.

Dessa forma, nota-se que as recomendações nutricionais variam em função de diversos fatores. Neste sentido, os pacientes necessitam de uma dieta que proporcione todos os nutrientes essenciais para a satisfação das suas necessidades nutricionais acrescidas e assim contribua quer para a prevenção da perda de peso ou manutenção deste, quer para o combate à infecção bem como para o desenvolvimento ou manutenção da massa muscular.

\section{Referências}

Abramovay, Miriam. (2015). Juventudes na escola, sentidos e buscas: Por que frequentam? 1 ed. Brasília: FLACSO-Brasil, OEI, MEC, 346.

Aggleton, P. P. A. \& Parker, R. (2015). "Moving beyond biomedicalization in the HIV response: Implications for community involvement and community leadership among men who have sex with men and transgender people". American Journal of Public Health. 105(8), 1552-1558.

Alves, D. V. S. (2019). Estado nutricional e capacidade funcional de pacientes com o vírus da imunodeficiência adquirida hospitalizados. DEMETRA, Rio de Janeiro, 14(34792), 1-14.

Azevedo, A. S., Oliveira, D. C., \& Soares, P. K. D. (2016) Perfil nutricional de pacientes adultos e idosos hospitalizados. Revista Saúde e pesquisa, Maringá (PR), 9(1), 25-29.

Barbosa, R. M. R (2018). Avaliação nutricional empacientes infectados pelo Vírus daImunodeficiência Adquirida. Rev. Nutr. 16(4), Campinas.

Bezerra, V. P., et al. (2016). Ações de prevenção do HIV e de Promoção à Saúde no contexto da AIDS pela Estratégia Saúde da Família em João Pessoa-PB. Ciênc. Cuid. Saúde. Paraíba, 15(2), 343-9.

Braga,I. S., Guimaraes,N. S., \& Figueiredo,S. M. (2015). Distúrbios nutricionais e metabólicos provocados pela utilização da terapia antirretroviral e abordagem nutricional: uma revisão narrativa. Nutr. clin.diet. hosp., Belo Horizonte, 35(1), 6-61

Brasil. (2016) Ministério da Saúde. Secretaria de Vigilância em Saúde. Boletim epidemiológico AIDS e DST. Brasília: Ministério da Saúde, 2016.

Brasil. (2013) Ministério da Saúde. Secretaria de Vigilância em Saúde. Departamento de DST, Aids e Hepatites Virais. Protocolo clínico e Diretrizes terapêuticas para adultos vivendo com HIV/AIDS. Brasília: Ministério da Saúde.

Calister. (2016). Estado nutricional e sarcopenia no doente com infecção VIH/SIDA. Nutr.clin.diet. hosp., Belo Horizonte, 45-61.

Costa, C. S., et al. (2019). Associação entre diferentes métodos de avaliação nutricional em pacientes com hiv/aids em um hospital público. Rev Bras Promoç Saúde, Fortaleza, 30(3), 1-9.

Cruz-Jentoft, A., et al. (2016). Sarcopenia: revised european consensus on definition and diagnosis.Age and Ageing, 48(1), 16-31.

Ferreira, M. G. (2019). História da homossexualidade ligada à transmissão de HIV/AIDS e abordagem na escola pelo filme Filadélfia de Jonathan Demme. Revista Discente Ofícios de Clio, Pelotas, 4(7), 124-130.

Filteau, S., et al. (2017). Nutritional status is the major factor affecting grip streng tho African HIV patients before and during antiretroviral treatment. Tropical Medicine \& International Health, 22(10), 1302-1313.

Fisher, C., et al. (2019). Estado nutricional de gestantes infectadas pelo HIV/AIDS: PERÍODO DE 2010 A 2015 . Revista Brasileira de Obesidade, Nutrição e Emagrecimento, São Paulo. 13(79), 400- 406.

Flores-Lopez, G., \& Flores-Arenales, I. (2020). Suplementación nutricional, ganancia ponderal en pacientes con VIH/SIDA. RevSalJal, 7(1), 34-40.

Galvão, A. L., et al. (2018). Estado nutricional e desfechos clínicos em pacientes hiv/aids internados em hospital de doenças infectocontagiosas. Revista de Ciências da Escola de Saúde, República Cândido Santiago, 4(1), 36-45.

Gonçalves, T. R., \& Piccinini, C. A. (2015). Contribuições de uma Intervenção Psicoeducativa para o Enfrentamento do HIV durante a Gestação. Psicologia Teoria e Pesquisa. 31(2), 193-201. 
Kubrusly, M., et al. (2015). Prevalence of Metabolic Syndrome according to NCEPATP III and IDF criteria in Patients on Hemodialysis. J Bras Nefrol, 37(1), 23-30.

Ledo, A. P. O., et al. (2017). Sarcopenia em uma amostra de indivíduos infectados HIV atendidos a nível ambulatorial. Revista Pesquisa em Fisioterapia, 7(3), 400-407.

Lenzi, L., et al. (2015). Adesão à terapia antirretroviral durante a gestação e sua relação com a efetividade na prevenção da transmissão vertical do HIV. Acta Biomedica Brasiliensia. 4(2), 12-20.

Lima, S. K. S. S., et al. (2017). Caracterização das gestantes com HIV/Aids admitidas em hospital de referência. Sanare. 16(1), 45-51.

Malta, D. C., et al. Política Nacional de Promoção da Saúde (PNPS): capítulos de uma caminhada ainda em construção. Ciênc Saúde Coletiva, v.21, n. 6, p. 1683-94, 2016.

Magnani, A. M. (2016). avaliação nutricional em paciente portadores do vírus da imunodeficiência humana. clinical \& biomedical research . 36(4), $214-221$. $8 \mathrm{P}$.

Melo, D. B. (2018). Estado nutricional, massa óssea, aptidão cardiorrespiratória, força muscular e populações linfocitárias de pacientes com imunodeficiência comum variável. Revista de Ciências da Escola de Saúde, República Cândido Santiago, 10, 70-73.

Moura, I.F.C. (2018). Indicadores nutricionais em pacientes portadores de HIV/SIDA / Nutritional indicators in patients with HIV/AIDS: ambulatorial and hospital reality. Nutr. clín. diet. hosp .38(1), 122-127.

Morales, M., Garcia, A. J. (2015). Toxicidad por fármacos antivirales. Rev Salud Qroo, 8(8), 23-27.

Moyer, E. (2015). "The Anthropology of after AIDS: epistemological continuities in the age of antiretroviral treatment". Annual Review of Anthropology, 44(4), 259-275.

Neves, M. A. (2016). Músculo adutor do polegar como ferramenta de avaliação nutricional em pacientes portadores do vírus da imunodeficiência humana. Clin Biomed Res, 36(4).

Niro, A. V. T. (2020). O paciente imunodeprimido e estratégias nutricionais. Rev. Bras. Enferm. São Paulo, 15-21.

Nogueira, L. F. R., et al. (2019). Transtornos Mentais Comuns estão associados a maior carga viral em Pessoas Vivendo com HIV. Saúde Debate, Rio de Janeiro, 43(121), 464-476.

Oliveira, E. C., Leite, J. L., \& Claro, F. P. S. (2015). A gerência do cuidado à mulher idosa com HIV/AIDS em um serviço de doenças infecto-parasitárias. Rev Enf Cent O Min [Internet], 3(2), 67-71.

Oliveira, C. F., et al. (2018). Avaliação subjetiva global versus avaliação antropométrica de pacientes com HIV. Motri, Ribeira de Pena, 14(1), 98-103.

Pereira, C. R., \& Monteiro, S. S. (2015). A criminalização da transmissão do HIV no Brasil: avanços, retrocessos e lacunas. Physis, 25(4), 1185-1205.

Pinto, G. S., et al. (2016). Nutritional status and food intake of HCV/HIV coinfected patients. Nutr. Hosp., 33(5), 45-51.

Gorzevcky, R. A. (2019). Avaliação do estado nutricional de pacientes com Síndrome da Imunodeficiência Adquirida (SIDA) hospitalizados no HCPA: resultados preliminares. Clin Biomed Res, 39.

Ribeiro, M. M. C., et al. (2015). Análise de diferentes métodos de avaliação do estado nutricional de pacientes em hemodiálise. Rev Cuid, Bucaramanga, 6(1), 932-40.

Santos, A., et al. (2020). Autopercepção da imagem corporal e avaliação do estado nutricional de pacientes que vivem com HIV/AIDS acompanhados em um hospital escola de Pernambuco. Braz. J.of Develop., Curitiba, 6(9), 70429-70445.

Santos, K. M.(2016). Intervenções nutrológicas em pacientes adultos infectados pelo vírus da imunodeficiência humana. thieme revinter, rio de janeiro, 25(6), 230-240.

Silva, A. A. A., et al. (2015). Prevalência de má nutrição e doenças oportunistas em pacientes HIV/Aids internados em um hospital de referência de Porto Velho- Rondônia. Saber Cientifico, Porto Velho, 4(1), 58-64.

Silva, A. F. C., \& Cueto, M. (2018) HIV/Aids, os estigmas e a história. Hist. cienc. Saúde. Rio de Janeiro, 25(2), 234-240.

Silva, A. G., et al. (2018). Revisão integrativa da literatura: assistência de enfermagem a pessoa idosa com HIV. Brasília, 71(2), 367-370.

Silva, G. L. F., et al. (2016). Nível de atividade física e Síndrome Lipodistrófica em pacientes com HIV/AIDS. Rev Bras Med Esporte, 22(2), 147-52.

Silva, T. B. D., \& Libonati, R. M. F. (2020). Ângulo de fase e indicadores do estado nutricional em pessoa vivendo com HIV/Aids com síndrome lipodistrófica secundária à terapia antirretroviral. Braz. J. Hea. Rev., Curitiba, 3(4), 10710-10727.

Soares, G. H. I. (2018). Nutrição voltada paciente imunodeprimiodos e sua relação com o aumento da imunidade. Einstein. São Paulo, 8(1), $102-206$.

Sousa, A. C. A., Suassuna, D. S. B., \& Costa, S. M. L. (2016). Perfil clínico-epidemiológico de idosos com Aids. DST J bras Doenças Sex Transm [Internet], 21(1), 22-6.

Sousa, A. I. A., \& Junior, V. L. P. (2016). Carga viral comunitária do HIV no Brasil, 2007-2011: potencial impacto da terapia antirretroviral (HAART) na redução de novas infecções. Rev. bras. epidemiol., 19(3), 76-83. 
Research, Society and Development, v. 10, n. 7, e4510716378, 2021

(CC BY 4.0) | ISSN 2525-3409 | DOI: http://dx.doi.org/10.33448/rsd-v10i7.16378

Souza, C. N., et al. (2018). Perfil nutricional de pacientes HIV/Aids hospitalizados. Multitemas, Campo Grande-MS, 23(53), 159-181.

Souza, M. T., Silva, M. D., \& Carvalho R. (2010). Revisão integrativa: o que é e como fazer. Einstein. São Paulo, 8(1), 102-6.

Thomaz, D. (2018). A outra pílula azul: o novo medicamento que está fazendo os gays abandonar o uso da camisinha. Época, 2(1031), 34-42.

Tshingani, K., et al. (2017). Impact of Moringa a lei fera $1 \mathrm{am}$. Leaf power supplementation versus nutritional counseling on the body mass in dex and immune response of HIV patients on antiretroviral therapy: a single-blind randomized control trial. BMC complementary and alternative medicine, $17(1)$, 420-24.

Verissimo, G. A. (2020). Nutrição e Imunodepimidos. Heart. Rev, Curitiba, 27-35.

Valle, C. G. (2018). Memórias, histórias e linguagens da dor e da luta no ativismo brasileiro de HIV/Aids. Sex., Salud Soc. Rio de Janeiro, 1(30), 45-46.

Zamboni, M. B. (2015). “AIDS, longa duração e o trabalho do tempo: narrativas de homens que vivem com HIV há mais de 20 anos”. Política \& Trabalho, Brasilia, 1(42), 69-90. 